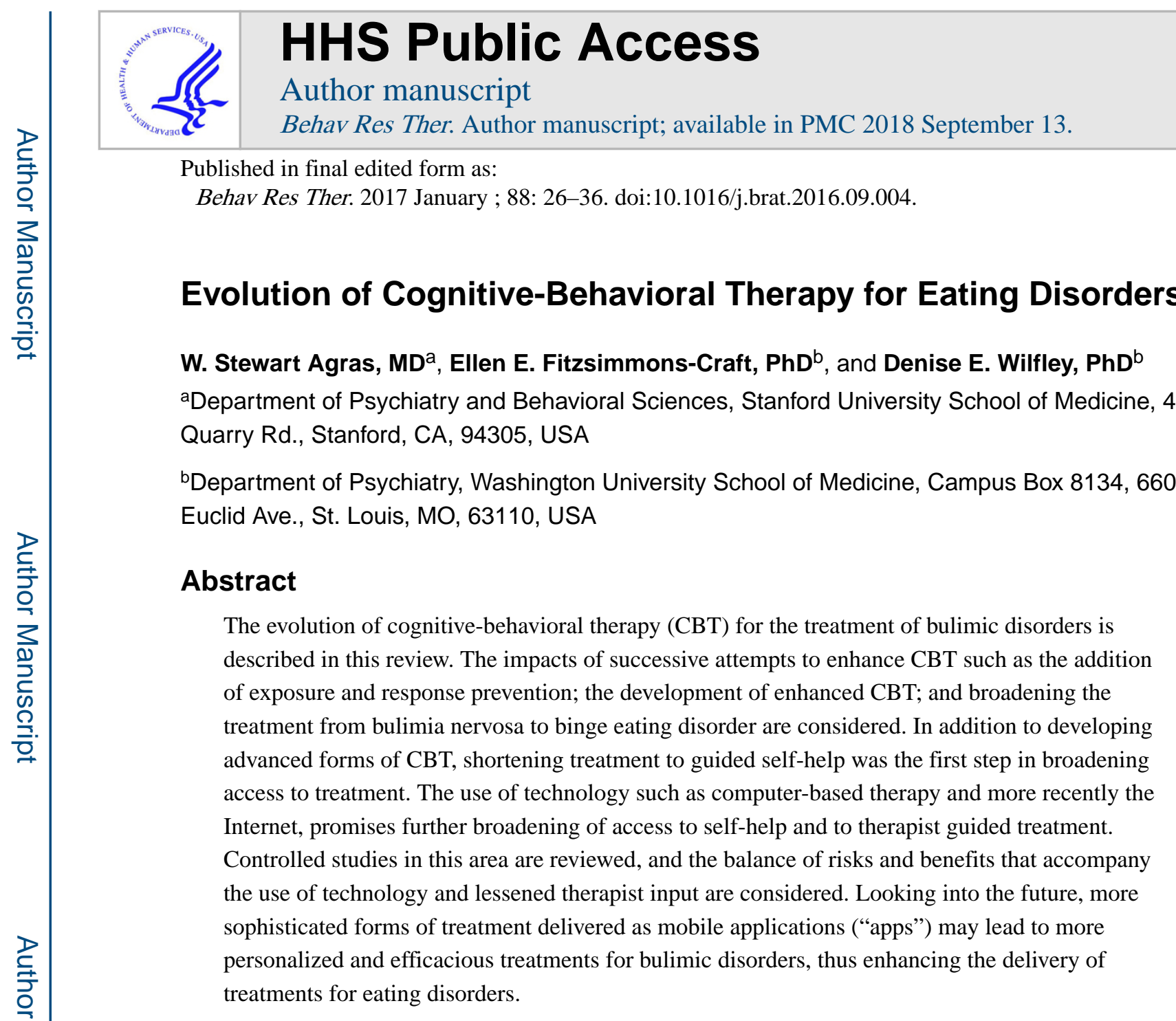

\title{
Keywords
}

eating disorder; cognitive-behavioral therapy; guided self-help; technology-based treatment; Internet-based treatment

In this paper, we trace the evolution of cognitive-behavioral therapy (CBT) for the treatment of bulimic disorders. The applications of a particular psychotherapy can be broadened in two ways. First, the treatment itself can be strengthened to become more effective. This may be

\footnotetext{
Correspondence concerning this article should be addressed to W. Stewart Agras, Tel: +1 650 725-5734 sagras@stanford.edu (W.S. Agras).

We have known Terry Wilson for many years and have much admired his grace and good humor in working with others, whether undergraduates or eminent researchers. Our first joint publication was in 1979 in a book deriving from a year at the Center for Advance Study in the Behavioral Sciences (Agras, Kazdin, \& Wilson. Behavior Therapy: Toward an Applied Clinical Science). This volume reflects a common thread in his work, namely, his interest in cognitive and behavioral processes, cognitive-behavioral therapy, work that is theory-driven, distinguishing him from others. This has led to seminal papers in which he is able to artfully synthesize a problem or field, bringing together numerous threads into a coherent whole. His renowned work in eating disorders over the last 25 years also includes numerous groundbreaking studies, from the development and evaluation of psychotherapies to the assessment of mechanisms and moderators. Our collaborative efforts have significantly impacted the field by elucidating the clinical significance and treatment of binge eating disorder, and we are now embarked on a major implementation science initiative to disseminate evidencebased research to practice. We have both been impacted greatly by Terry's sage appraisal of the field and innovative solutions. His passion for research, learning, mentoring, and evidence-based treatment is ever-present and contagious. Stewart Agras and Denise Wilfley

Email addresses: fitzsimmonscrafte@ psychiatry.wustl.edu (E.E. Fitzsimmons-Craft),wilfleyd@psychiatry.wustl.edu (D.E. Wilfley)
} 
achieved by strengthening identified or hypothesized mechanisms underlying the treatment's effects, more precisely identifying for whom the treatment works best, by adding new modules to the treatment or removing ineffective modules, or by broadening effectiveness to treat a wider array of disorders. Second, the original treatment can be modified to provide easier access for a greater number of affected individuals or be modified to reduce costs associated with the treatment, for example, by reducing therapist contact time. Shortening treatment duration and reducing the role of the therapist in the interest of reduced cost and wider availability does however raise ethical and pragmatic issues in terms of implementation, safety, and effectiveness. Unless otherwise stated, intent-to-treat analyses are presented throughout this paper.

\section{Bulimia Nervosa}

Russell in his seminal paper in 1979 drew attention to the clinical characteristics of bulimia nervosa (BN), and like most clinical scientists at the time, linked the syndrome to anorexia nervosa (AN) (Casper, Eckert, Halmi, Goldberg, \& Davis, 1980; Guiora, 1967; Russell, 1979). However, the first application of cognitive-behavioral therapy (CBT) (Fairburn, 1981) to this disorder recognized the distinctive treatment targets for $\mathrm{BN}$ such as dietary restriction and shape and weight concerns. Two early randomized controlled trials (RCTs) compared CBT to short-term focal therapy, behavior therapy, and interpersonal psychotherapy (IPT) (Fairburn et al., 1991; Fairburn, Kirk, O'Connor, \& Cooper, 1986)). Another early trial compared CBT and supportive-expressive psychotherapy (Garner et al., 1993). Overall, CBT appeared more effective than alternative treatments in these studies although the differences were not large. Typical of an early stage of development, sample sizes were small (12 to 30 participants per group), and two studies used completer analyses (Fairburn et al., 1986; Garner et al., 1993). Although CBT was more effective than IPT post-treatment, longer-term follow-up suggested that IPT might be equally effective, although at 12 -months only about half the sample $(\mathrm{N}=37)$ was available for assessment from the original sample $(\mathrm{N}=75)$ (Fairburn, Jones, Peveler, Hope, \& O’Connor, 1993a).

While at the Center for Advanced Study in the Behavioral Sciences in 1976, Wilson, Fairburn and Agras designed a study to test whether CBT was in fact superior to other treatments for BN. The only other psychotherapy contender at the time was IPT. Hence the final design chosen was a comparison of CBT and IPT for the treatment of BN with a sufficient sample size $(\mathrm{N}=220)$. This sample size required two treatment sites in order to recruit enough participants in a reasonable timeframe, together with an external quality control center at Oxford University focused on treatment fidelity. CBT was found superior to IPT at end-of-treatment, with $29 \%$ vs. $6 \%$ recovered, but at follow-up there was not a statistically significant difference between groups with $40 \%$ recovered with CBT and 27\% with IPT (Agras, Walsh, Fairburn, Wilson, \& Kraemer, 2000). These findings confirmed those of the previous comparisons of the two treatments (Fairburn et al., 1993a; Fairburn et al., 1986).

In a follow-up analysis of these findings, Wilson et al. (2002) found that early response to treatment, measured by a decrease in self-induced vomiting during the first few weeks of treatment, predicted outcome, with CBT significantly superior to IPT by week 4 of 
treatment. Early identification of poor response to treatment allows for early addition of a new or modified treatment for those individuals. In addition, change in dietary restraint was found to mediate treatment outcome, with CBT significantly superior in reducing dietary restraint compared with IPT. This was the first time that a mechanism underlying the effectiveness of CBT in treating BN had been found and suggested that CBT had a specific effect on restraint. No mechanism underlying the effects of IPT on BN was found, for example, change in interpersonal interactions did not mediate outcome as might have been expected. Wilson et al. (2002) raised the question whether IPT did in fact "catch-up" with CBT over time. Part of the catch-up as illustrated in the primary paper (Agras et al., 2000) was due to a slight decrement in the mean effect of CBT on binge eating and vomiting over the follow-up period. As Wilson noted, however, "The posttreatment course of patients who received IPT does not appear different from that of patients who received CBT when the posttreatment levels of symptoms are considered. Similar fractions of patients who were recovered, remitted, or not remitted at the end of treatment had recovered by the end of follow-up in both treatments." Hence, there was no evidence of a catch-up effect.

\section{Enhancing CBT}

An early effort to enhance CBT involved adding a module to increase exposure to feared foods, hence reducing dietary restraint. In-vivo exposure was added to some or all treatment sessions, allowing the anxiety associated with exposure to dissipate within session when compensatory behavior such as self-induced vomiting was prevented. The first study to examine the effects of this treatment compared CBT to an exposure/response prevention condition (Wilson, Rossiter, Kleifiled, \& Lindholm, 1986). This was a small-scale study $(\mathrm{N}=17)$ with four dropouts precluding comparative analyses of binge eating and purging. There was, however, some indication of advantage for exposure/response prevention in terms of reducing binge eating and purging. A further study (Leitenberg, Rosen, Gross, Nudelman, \& Vara, 1988) compared 24 sessions of exposure/response prevention to CBT to a wait-list control in 47 women with BN. No difference was found between response prevention and CBT in reducing self-induced vomiting at post-treatment in a completer analysis. However, at follow-up response prevention showed a within-group change in selfinduced vomiting whereas CBT did not, again a possible signal of efficacy. A third study with 77 participants randomly allocated to 4 groups found (in a completer analysis) that CBT was superior to no treatment in reducing self-induced vomiting whereas exposure/ response prevention added to CBT was not (Agras, Schneider, Arnow, Raeburn, \& Telch, 1989). This finding may have been due to the displacement of elements of CBT by exposure/response prevention thus weakening the effect of CBT in that group. It should be noted that these studies differed in the amount of exposure/response prevention given within treatment and that the studies were small. Thus, the evidence for the effectiveness of exposure/response prevention was weak and was not adequately tested by today's standards.

\section{Broadening the Application of CBT}

Clinical and epidemiological studies suggested that binge eating often occurred separately from purging suggesting the existence of a hitherto unrecognized eating disorder (Halmi, Falk, \& Schwartz, 1981). Later, Spitzer drew attention to the new syndrome in a comment 
on a controlled study of desipramine for "non-purging BN" (McCann \& Agras, 1990). In his comment, Spitzer noted that a field trial for DSM-IV had found that "Binge Eating Disorder" (BED) was prevalent in weight-loss clinics and particularly affected women (Spitzer, 1991). A controversy then arose as to whether there was enough evidence for the new syndrome to be included in DSM-IV (Fairburn, Welch, \& Hay, 1993b; Spitzer et al., 1993) with the ultimate decision that further evidence was needed before inclusion of the disorder in the DSM. However, similarities between BN and BED in terms of symptoms, i.e. binge eating, dietary restraint, and weight and shape concerns, suggested that CBT and IPT might be effective treatments for BED, paving the way for a new series of controlled clinical trials. Hence, research into the treatment of BED was largely focused on the comparative effectiveness of CBT and IPT. The first small-scale study compared CBT provided in a 10session group format to a wait-list control condition for the treatment of BED (Telch, Agras, Rossiter, Wilfley, \& Kenardy, 1990) finding in a completers analysis that $79 \%$ of those receiving CBT were abstinent at the end-of-treatment compared with none of the controls. This study was followed by a comparison of CBT and IPT, both in a group format, together with a wait-list control group (Wilfley et al., 1993). The sample size was small $(\mathrm{N}=56)$ but both active treatments were superior to the wait-list control group but were not statistically different from each other in reducing binge eating either at end-of-treatment or at 12-month follow-up. Larger studies confirmed these early results. In one such study, 162 patients with BED were randomly assigned to either CBT or IPT (Wilfley et al., 2002). The two treatments were equivalent in reducing binge eating and in producing abstinence from binge eating at both end-of-treatment (CBT 79\%, IPT 73\%) and 1-year follow-up with some relapse (CBT 59\%, IPT 62\%). As in most studies, abstinence rates were higher than those obtained in the treatment of BN. This may be due to the high placebo response rate of BED compared to BN (about 38\% to 8\%) (Blom, et al., 2014).

\section{Refining CBT}

Fairburn, in his revision of the original CBT manual describing Enhanced Cognitive Behavioral Therapy (CBT-E), laid out the most ambitious effort to enhance the effectiveness of this treatment (Fairburn, 2008). CBT-E is embedded within a transdiagnostic view of the eating disorders and is therefore aimed at all eating disorders with some adaptations for different disorders and ages. Two forms were described: A focused treatment similar to the original manual (CBT-Ef) and a broad treatment (CBT-Eb). The broad form contains extra modules to address perfectionism, low self-esteem and interpersonal difficulties issues that contribute to the maintenance of eating disorders. In both forms, the therapist checks progress early in the course of treatment and makes appropriate adjustments to treatment if progress is not satisfactory. In a controlled comparison of the two forms of CBT and a waiting list in a substantial sample of diverse eating disorders (except AN), the two forms of CBT were superior to a waitlist but did not differ from each other (Fairburn, Cooper, \& Palmer, 2009). However, in a secondary analysis, participants with greater severity in attributes such as mood intolerance, perfectionism, interpersonal difficulties, and low selfesteem did better with CBT-Eb. A recent controlled trial compared the two forms of CBT in 50 patients with $\mathrm{BN}$ and comorbid affective/interpersonal problems (Thompson-Brenner et al., 2016). No differences were found between the two forms of CBT. However, patients 
with more severe affective/interpersonal problems recovered better with the broader form of CBT. The overall remission rate was $42 \%$. These studies suggest that for most patients with $\mathrm{BN}$ there is little difference between the two forms of CBT-E. However, for patients with more severe co-morbid psychopathology the broad form of CBT-E appears superior. Another recent controlled trial compared CBT-E and IPT in 130 adults with any form of eating disorder. At post-treatment, significantly more individuals in CBT-E (66\%) met criteria for remission compared to IPT (33\%). Over follow-up, remission rates increased in both conditions, particularly in IPT, but CBT-E remission rates remained significantly higher (69\% in CBT-Ef vs. 49\% in IPT) (Fairburn et al., 2015).

The general consensus is that CBT is more effective than other psychotherapies in the treatment of BN and should, therefore, be the preferred psychotherapeutic treatment (Hay et al., 2014). Moreover, the research literature has some notable strengths including the development of detailed treatment manuals, standardization of outcome measures particularly the use of the Eating Disorder Examination (EDE), comparisons of CBT with other active treatments rather than waitlist controls, and the use of multisite studies. There are, however, some methodological issues to consider. First, with some notable exceptions, the sample sizes for many studies have been, and even today are often small. Hence, differences in outcomes between treatments may not have been detected or may have been falsely detected. Second, few studies have identified the behavioral mechanisms underlying treatment that may enhance treatment effects if the mechanism can be strengthened. In addition, few studies have identified moderators of outcome that potentially allow improved selection of patients for particular treatments. Because of this no eating disorder studies have tested the effects of using a moderator to allocate individuals to the preferred treatment. Third, allegiance effects may pose a problem, possibly overestimating the effectiveness of treatment. This may be due to the use of therapists with greater expertise for the favored treatment than the comparison treatment or to therapist expectancy effects. Controlling for such biasing effects is difficult although multisite studies and the use of outside sites for training and monitoring fidelity of the treatment procedures may be helpful. Overall however, efforts to improve the outcome of treatment for bulimic disorders have not increased recovery rates by very much (Steinhausen $\&$ Weber, 2009).

With evidence-based treatments available the question of dissemination beyond specialized treatment centers arises. As Insel pointed out: "We have powerful, empirically-supported psychosocial interventions, but they are not widely available...A serious deficit exists in training for empirically supported psychosocial interventions...Translational research will need to focus not only on "bench to bedside" but also on bedside to practice" (Insel, 2009). However, the problem goes beyond dissemination of a treatment to its actual use by community psychotherapists. Three issues regarding wider dissemination of therapy have been delineated: Breadth of therapeutic effects, ease of training therapists, and mode of treatment delivery (Fairburn \& Wilson, 2013). For example, CBT-E is not easy to learn, requires specific training and supervised practice, is focused solely on eating disorders, and at 18 -sessions is not practicable in many community clinical settings. Interpersonal psychotherapy shares these characteristics although it has broader effects beyond eating disorders, namely, in treating depression and anxiety disorders without modifying the treatment. Hence, one solution to extending the range of these treatments would be to deliver 
them in a less complex form with fewer sessions and preferably with less highly qualified therapists to increase availability in a wider array of community settings. Guided self-help (gsh) is one promising adaptation of CBT allowing broader implementation.

In a timely paper, Wilson reviewed the effectiveness of therapist-guided self-help based on CBT for the treatment of BN and BED as a first step in providing treatment more widely (Wilson \& Zandberg, 2012). Guided self-help uses a treatment manual designed for patient use with the therapist acting as a coach. Hence, the patient may be more likely to attribute responsibility for treatment effects to themselves rather than to the therapist. Some studies have involved therapists with little experience with eating disorders and most have shortened therapist contact time. For example, in a large multisite RCT comparing CBT with CBTgsh ( $N=293$ ), the average contact time for CBT was 16-17 hours compared with 2-3 hours for CBTgsh (Mitchell et al., 2011). This study also throws light on a possible stepped-care model. Participants predicted to be non-responders, depending on the level of reduction of purging at week 6 of treatment (Wilson et al., 2002), in each of the treatment groups were offered fluoxetine plus continued psychotherapy or continuation of psychotherapy without a secondary treatment. There was no difference in outcome at end-of-treatment between the CBT and CBTgsh, however medication use was less with CBTgsh than with CBT. At follow-up, CBTgsh was significantly superior to $\mathrm{CBT}$ in reducing binge eating and compensatory behaviors. Use of the stepped-care model including CBTgsh would not only be an effective treatment modality but would also be substantially less costly than CBT.

Observations from weight loss treatments that binge eating declined during the course of treatment suggested that weight loss (WL) treatment for BED may be an effective and easily implementable treatment alternative to CBT or IPT. Small-scale studies with short-term follow-up confirmed this impression (Agras et al., 1994; Marcus, Wing, \& Fairburn, 1995). In a larger-scale study, 205 patients with BED were randomly allocated to either IPT, CBTgsh, or WL treatment with a follow-up of 2-years (Wilson, Wilfley, Agras, \& Bryson, 2010). There were no differences between the 3 treatments in reducing binge eating and eating disorder psychopathology at end-of-treatment or at 1-year follow-up. Weight loss treatment, on the other hand, was more effective in producing weight loss at 1-year followup. However, at 2-year follow-up both IPT and CBTgsh resulted in greater remission from binge eating than WL and weight change was no different between groups. A moderator analysis showed that IPT was more effective than CBTgsh in producing remission in patients with lower self-esteem and higher rates of eating disorder psychopathology.

Wilson and Zandberg (2012) concluded that CBTgsh is a promising evidence-based treatment for BN and BED, applicable to a wide range of settings and acceptable to diverse populations. CBTgsh should not only be considered as a first step in a stepped-care approach but should be viewed as an evidence-based treatment in its own right. Hence, CBTgsh is a treatment that meets many of the criteria for scalability: it is easy to learn, can be effectively taught to relatively inexperienced clinicians, can be provided in 2 or 3 -hours and is therefore cost-effective. 


\section{A Missing Link}

The development and testing of evidence-based treatment for eating disorders adapted for use in community clinical settings has lagged behind efficacy research in more highly controlled settings. Several uncontrolled studies have shown that CBT or CBT-E can be utilized effectively in community clinics (Turner et al., 2015; Waller et al., 2014), however these studies used a greater number of treatment sessions than would be applicable in many community clinics because of financial constraints. Few controlled effectiveness studies have been carried out in community settings where the need for shorter focused treatments is greatest. Such studies require training community therapists following which a controlled trial comparing the evidence-based treatment with usual community care is needed. Only if the evidence-based treatment is superior to usual care, and the treatment was carried out with reasonable fidelity, should it be implemented more widely.

One of the reasons that this type of research is so rare is the complexity involved in organizing and executing such studies. Hence, the Director and staff of the community site chosen must be able to see the study as having some advantage and should have input into the therapy to be used and the feasibility of the experimental design. The next step is to insert the requirements of the study into the clinic's practices. This requires screening potential patients, securing their formal consent to participate, randomizing them to treatment conditions and assessing patient progress (for which abbreviated measures may need to be used). In addition, assessment of therapist fidelity to the treatments is required.

A study carried out in a large community clinic had an adequate sample size with 160 participants with BED randomly allocated to either CBTgsh or treatment as usual (Debar et al., 2011). At end-of-treatment, 33\% of the CBTgsh group and 5\% of the treatment as usual group were abstinent, a significant difference that persisted to 12-month follow-up.

However, treatment as usual appeared to be close to a waiting list control and the study did not therefore compare CBTgsh to an active community treatment.

\section{Using Technology to Broaden Access to Treatment}

The availability and use of computers, the Internet, and mobile phones have expanded tremendously. In 2014, nearly 90\% of U.S. adults accessed the Internet ("Internet users," n.d.), and as of 2015, $68 \%$ of U.S. adults had a smartphone, up from $35 \%$ in 2011 (Anderson, 2015). As access has grown so has the functionality of technology and at the same time, technological advances have become less expensive, more compact, and more powerful (Kurzweil, 2010).

With the rise of technology, CBT for eating disorders has also seen advances. E-mental health refers to the delivery or enhancement of mental health services through technology, particularly the Internet (Lal \& Adair, 2014). E-mental health has numerous purported benefits including: lack of geographic boundaries, allowing for widespread dissemination and the ability to reach individuals who may otherwise have limited access to effective treatment (e.g., those in rural communities) or who may not seek help due to shame or fear of stigma; easy access from anywhere at anytime; cost and time efficient; and high user 
acceptability (Aardoom, Dingemans, Spinhoven, \& Van Furth, 2013; Dölemeyer, Tietjen, Kersting, \& Wagner, 2013). Only a small proportion of individuals with eating disorders seeks or receives treatment-according to one systematic review, only $23 \%$ of community cases with a diagnosable eating disorder seek eating disorder-specific treatment (Hart, Granillo, Jorm, \& Paxton, 2011), and Eisenberg, Nicklett, Roeder, and Kirz (2011) found that less than $20 \%$ of college students who screen positive for an eating disorder report receiving treatment. Hence, there is a large unmet need for treatment, and as highlighted by Wilson and colleagues (Fairburn \& Wilson, 2013; Wilson \& Zandberg, 2012), technology has the potential to make evidence-based treatment for eating disorders, such as CBT, more widely available and to address barriers to care. There has been a growing number of reviews on the use of technology, the Internet, and mobile applications ("apps") for the treatment of eating disorders (i.e., Aardoom et al., 2013; Aardoom, Dingemans, \& Van Furth, 2016; Ambwani, Cardi, \& Treasure, 2014; Bauer \& Moessner, 2013; Dölemeyer et al., 2013; Fairburn \& Rothwell, 2015; Loucas et al., 2014; Schlegel, Bürger, Schmidt, Herbst, \& Voderholzer, 2015; Shingleton, Richards, \& Thompson-Brenner, 2013). Given the focus of the current paper on the evolution of CBT for eating disorders, we focus our overview specifically on RCTs that have utilized technology for CBT delivery with individuals with clinical eating disorders (see Table 1).

\section{CD-ROM RCTs.}

The first technology to be used for the delivery of CBT for eating disorders was the CDROM, and two RCTs have tested this delivery format. Schmidt et al. (2008) compared a selfhelp CD-ROM CBT program to a waitlist control condition among 97 adults with bulimictype disorders. The program consisted of eight 45-minute modules, and CD-ROM modules were completed on-site at an eating disorders program. Uptake of and engagement with the CD-ROM was suboptimal, and post hoc comparisons of group differences on the outcome variables at end-of-treatment and 4-month follow-up showed no significant differences. Shapiro et al. (2007) compared a different self-help CD-ROM CBT program with in-person group CBT and a waitlist control in a sample of 66 overweight adults with full or subthreshold BED. At post-treatment, there were no significant differences between conditions on most outcome measures. However, there was a significantly greater decline in binge days in the two active conditions compared to the control. Furthermore, over twothirds of those in the CD-ROM condition reported using the program after study completion, and $75 \%$ of those on the waitlist chose to receive the CD-ROM over group treatment.

\section{Email RCTs.}

Around the same time as the CD-ROM was being tested as a way to deliver unguided CBT for eating disorders, researchers were also exploring email as a vehicle for therapist input in two RCTs. Ljotsson et al. (2007) compared Internet-assisted self-help (CBT self-help book plus once- to twice-weekly email contact with a psychology graduate student for support and feedback and access to an online discussion group) to a waitlist control in a sample of 73 adults with full or subthreshold BED. Analyses revealed that $37 \%$ of treated individuals were abstinent from binge eating and purging at end-of-treatment (vs. 15\% of waitlist), with marked improvement on secondary outcome measures in comparison to waitlist. Robinson and Serfaty (2008) conducted the first RCT of psychotherapy for eating disorders delivered 
via email, testing whether email-based CBT was superior to self-directed writing or waitlist control conditions in 97 adults with BN, BED, or eating disorder not otherwise specified (EDNOS). At end-of-treatment, significantly fewer participants in email-based CBT or selfdirected writing met criteria for an eating disorder compared to waitlist. Participants in the study were recruited from a university population via mass email. Thus, this study suggested that not only may email-based therapy be efficacious but also that email may provide a vehicle to reach individuals who may not otherwise seek or receive treatment, as the authors speculated that their recruitment approach was successful in recruiting one-fifth of all people at the college who were likely to have an eating disorder.

\section{Internet RCTs.}

To date, there have been seven RCTs of Internet-based CBT (iCBT) for eating disorders.

Three studies have investigated the effects of Internet-based programs on bulimic symptoms specifically. First, Sánchez-Ortiz et al. (2011) compared iCBT with therapist guidance in the form of supportive emails (amounting to 45 minutes of therapist time per participant on average) to waitlist control in a sample of 76 college students with bulimic-type disorders. iCBT was found superior to waitlist in terms of reductions in global eating disorder pathology, binge eating, affective symptoms, and quality of life, and these gains were maintained or even continued to improve at 3-month follow-up. Nearly $40 \%$ of those in the iCBT condition were abstinent from bulimic behaviors at follow-up, and over half no longer met diagnostic criteria for an eating disorder. Over $75 \%$ in the iCBT condition started treatment and, among those who completed at least one session, the mean number completed was five out of a possible 8 sessions.

Second, Ruwaard et al. (2013) found iCBT, including 25 scheduled online therapist feedback episodes taking roughly 13 hours to complete, to be more effective than both a waiting list and unguided bibliotherapy in terms of reductions in binge eating, purging, and global eating disorder symptoms at end-of-treatment in a sample of 105 adults with bulimic symptoms. Abstinence from purging at end-of-treatment was significantly greater in iCBT (39\%) vs. bibliotherapy and waitlist ( $8 \%$ in both), although there were no differences between groups in binge eating abstinence. Improvements in the iCBT group were sustained at one-year follow-up, but differences between iCBT and bibliotherapy were no longer significant due to improvements among those in bibliotherapy.

Third, Wagner et al. (2013) compared guided iCBT and bibliotherapy in a sample of 155 adult females with bulimic disorders. In both conditions, weekly email support from a therapist was provided. The treatments were equally effective for reducing binge eating and vomiting. At end-of-treatment, nearly 50\% of participants were in remission from eating disorder symptoms and nearly $20 \%$ were abstinent in both conditions.

Two studies have tested the effects of Internet-based programs for BED. First, Carrard et al. (2011) tested iCBT for BED, comparing guided iCBT to a waitlist control among 74 adult women with full or subthreshold BED. Coaches provided weekly support via email during the active intervention phase and monthly email support during the follow-up period.

Compared to waitlist, participants in iCBT showed superior reductions in binge eating, drive for thinness, and body dissatisfaction, as well as improvements in self-esteem and quality of 
life. Further, after the 6-month iCBT intervention, 35\% of participants were abstinent from eating disorder symptoms compared to just $8 \%$ in the waitlist condition. Gains were sustained or continued to improve at 6-month follow-up. The authors noted adherence to be satisfactory, although only one-third completed the program. Second, Wagner et al. (2016) compared iCBT to waitlist in 139 adults with BED. Binge eating episodes, eating disorder psychopathology, depressive symptoms, and weight loss showed significant improvement at end-of-treatment in iCBT vs. waitlist, and notably, all gains were sustained in iCBT at 1year follow-up.

A further study compared iCBT to waitlist control in a mixed-diagnostic sample of 214 adult females (ter Huurne et al., 2015). Previous versions of iCBT tested utilized weekly sessions, with session length typically close to the length of standard face-to-face therapy sessions. In contrast, ter Huurne designed an intervention with daily sessions that took approximately 20 minutes per day to complete. Participants had contact with their assigned therapist, who provided feedback on program use and support via the program website. Compared to waitlist, those in iCBT improved significantly more on global eating disorder psychopathology, as well as body dissatisfaction, self-esteem, and social functioning. Further, the effects of iCBT were compared between patients with different eating disorder diagnoses (i.e., BN, BED, EDNOS), revealing that $\mathrm{iCBT}$ was primarily effective for participants with BED.

Finally, Aardoom et al. (2016) studied the effects of adding different levels of therapist support, via e-mail, chat or teleconference, to a web-based self-help program (Featback). Therapist support varied from none to weekly and 3 times/weekly. Participants were recruited and assessed via a website, and the 354 participants included all eating disorder diagnoses including AN, BN and BED. The fully automated self-help program was broadly based on CBT principles with a duration of 8-weeks and follow-up to 6-months posttreatment. Eating disorder psychopathology improved in all Featback conditions and was superior to waitlist. There appeared to be no added value to therapist support in clinical outcomes including dropouts although those who received support were significantly more satisfied with treatment.

\section{Further evolution of CBT for eating disorders.}

As described, there are a limited, but growing number of published controlled trials on the use of iCBT for eating disorders. This research is in its infancy, and additional studies with stronger methodology are needed, as the majority compared iCBT to waitlist. There are, however, several ongoing efforts with stronger control conditions. In an ongoing noninferiority trial, Bulik and colleagues (2012) are comparing an Internet-based version of group CBT for BN (CBT4BN), in which the group intervention is conducted via a therapeutic chat group, and traditional face-to-face group CBT. de Zwaan et al. (2012) are currently testing the noninferiority of an Internet-based guided self-help CBT program for individuals with BED to face-to-face CBT. Although non-inferiority trials are often used, there is a potential problem with such trials. It is possible that a treatment A will not be inferior but will also be not quite as effective as the standard treatment. If treatment $A$ then becomes standard, a treatment B compared to A may again not be inferior but not quite as 
effective. Hence beginning a race to the bottom. Finally, in an ongoing RCT, Student Bodies-Eating Disorders (SB-ED) is being tested to determine whether it yields measurable and significant improvements in access, costs, and outcomes over referral to usual care among college women with clinical or subclinical eating disorders, with the exception of AN (Wilfley et al., 2013). The intervention is a CBTgsh program, utilizing brief 10-15 minute daily sessions, that is offered both via an Internet-based platform and mobile app. Previous work has established the program's initial efficacy for reducing eating disorder psychopathology, weight concerns, binge eating, and purging (Jacobi, Völker, Trockel, \& Taylor, 2012; Jones et al., 2008; Saekow et al., 2015).

\section{From the Internet to mobile applications.}

The next evolution in the delivery of CBT for eating disorders is the mobile app. Research suggests that Americans now use smartphone apps more frequently than personal computers to access the Internet (O'Toole, 2014) and that consumers spend over $85 \%$ of their time on smartphones using apps (Perez, 2015). Just as the Internet made interventions more accessible in comparison to CD-ROM-delivered programs, apps may make CBT more accessible given their portability, high level of functionality and interactivity, and capacity for in-the-moment intervention in the real world (Heron \& Smyth, 2010; Juarascio, Manasse, Goldstein, Forman, \& Butryn, 2014). There are several potential roles for apps. They may be used solely to monitor change in symptoms or other important features of a particular syndrome. Feedback can then be provided to both patient and therapist. They may also be used to enhance behavior changes between therapy sessions or to provide coping skills for use in particular situations. Such usages may reduce therapist time and enhance outcomes. They may be used to deliver self-help as well. Whether apps should be used as a primary treatment, i.e. with no therapist involved, is uncertain at the moment. One factor to take into consideration is the seriousness of the disorder. Hence, in eating disorders neither AN nor BN would appear suitable for stand-alone, unguided app treatment because of safety concerns. Moreover, treatment implies the ability to continuously consider when and how to provide a therapeutic application, something beyond the capability of present day apps, and apps aimed at treatment would need to be evaluated in controlled clinical trials. Indeed, a recent review of smartphone applications for the treatment of eating disorders found that existing, publicly available apps contained minimal CBT techniques, failed to incorporate smartphone capabilities, and none had been well evaluated (Juarascio et al., 2014)

\section{Comment}

Hsin, Torous, and Roberts (2016) in their consideration of an adjuvant role for mobile health in the management and treatment of mental health conditions note, "Within the present climate of limited clinical evidence and lack of regulatory oversight for mobile mental health, there is a clear need for safeguards ... to ensure safe, effective, and ethical use of technology." The controlled Internet-based treatment studies for bulimic conditions listed in Table 1 offer a starting point to consider effectiveness, acceptability, and safety of such interventions. Internet-based treatment offers a potentially large improvement in access to CBT. The need for psychological services for eating disorders is large, and only a small proportion of individuals in need receive treatment. However, reductions in safety, 
acceptability, and effectiveness, as the role of therapist is diminished, should not outweigh the benefit of wider treatment availability.

\section{Safety.}

$\mathrm{BN}$ and BED are associated with considerable current and lifetime comorbid psychopathology including: major depression, obsessive-compulsive disorder and other anxiety disorders, and addictive behaviors, as well as physical disorders consequent upon the eating disorder. Hence, there is a need for accurate diagnosis and expert guidance when offering treatment to persons with an eating disorder. Six of the studies listed in Table 1 used face-to-face assessments at baseline with standard diagnostic instruments (Carrard, et al., 2011; Ljotssen et al., 2007; Ruwaard et al., 2013; Sanchez-Ortiz et al., 2011; Shapiro et al., 2007; Wagner et al., 2013). Two studies used telephone screening using standard assessments (Schmidt et al., 2008; Wagner et al., 2016), and three studies conducted all assessments online using questionnaires without direct contact with participants. (Aardoom et al., 2016; Robinson \& Serfaty, 2008; ter Huurne et al., 2015). In one of these studies (Robinson \& Serfaty, 2008), the ethics committee raised concerns that "some individuals might feign illness and be accepted to the study or that some with psychological difficulties may become worse during treatment..." and may go undetected. Interestingly, none of these studies used Skype or video-conferencing to assess participants. Telephone assessments have been shown to be reasonably reliable particularly in detecting more severe cases of depression (Simon, Revicki, \& VonKorff, 1993), an important issue because suicidal ideation was considered an exclusion for Internet treatment in these studies. However, important visual and interpersonal clinical signs may not be apparent within a telephone interview.

For BN in particular, medical screening prior to entry into treatment is needed, and for AN medical screening and ongoing medical monitoring is essential. Two of the Internet-based studies described the use of a medical examination together with appropriate blood tests prior to study entry (Sánchez-Ortiz et al., 2011; Wagner, et al., 2013). The only study that enrolled patients with AN did not report medical screening or ongoing monitoring (Aardoom et al., 2016). It is, of course, possible that medical procedures were adequate but not noted in the description of the remaining studies. Assessment of adverse events during the course of the study was also unusual in that only two studies provided such assessment (Aardoom et al., 2016; Sánchez-Ortiz et al., 2011). Detection and monitoring of adverse events should be routine in controlled treatment outcome studies. It is important to distinguish between the use of the Internet for prevention of eating disorders and for the treatment of eating disorders. The Internet is useful for prevention programs applied to segments of the general population and while adverse events should be monitored, the risks associated with prevention programs are usually small.

Detection of comorbid pathologies is also important given the high prevalence of such disorders in bulimic syndromes. This would be the usual standard of care for a clinical consultation. The optimal method of screening is a face-to-face interview with trained personnel and should be the standard for Internet treatment in general and for the next generation of controlled studies. Acceptable forms of face-to-face assessment beyond a 
direct interview might be via Skype or teleconference. In addition, some method of monitoring comorbid psychopathology throughout treatment should be instigated so that changes throughout therapy can be followed. Consideration should be given to withdrawing participants who show lack of progress or worsening of primary or comorbid psychopathology and providing specialized care. As noted, medical safety is also important for participants with bulimia nervosa. Medical history, physical examination to the extent needed, and necessary blood tests should be obtained for controlled treatment studies including Internet therapy. Such medical clearance could be assessed either at the study site or by the participant's family physician who would then provide written clearance for participation. In some respects, the lack of geographic boundaries when it comes to the delivery of technology-based interventions is a strength, but careful consideration needs to be given to issues of assessment and medical clearance so as to maximize participant safety.

The following issues also need to be considered: making referrals to in-person care when an individual lives in an area without evidence-based treatment for eating disorders available; legality of providing services across state lines; and risks to breach of confidentiality. This work is in its early days, and firm recommendations regarding the use and safety of these programs are not yet available. However, there are a number of emerging sets of guidelines on the ethics of using technology for mental health intervention that should be consulted (see Table 2).

\section{Acceptability.}

Five of the Internet-based controlled outcome studies evaluated acceptability. Formal acceptability ratings were made in 4 studies (Ruwaard et al., 2013; ter Huurne et al., 2015; Wagner et al., 2013). In one study, $81 \%$ of participants viewed the intervention as rather or very useful, and $77 \%$ of participants rated the online therapist as pleasant, $60 \%$ as personal, and $92 \%$ as safe (ter Huurne et al., 2015). On a rating scale from 1-10 with 1 as the lowest response, participants in another study rated the overall value of the therapy as $7.5(\mathrm{SD}=1.3)$, Internet therapist contact was rated as $8.6(\mathrm{SD}=1.9)$, and $76 \%$ had not missed face-to-face contact (Ruwaard et al., 2012). Another study found that $54 \%$ of participants rated the treatment as very helpful, with a very low percentage (3\%) rating treatment as not helpful (Wagner et al., 2013), and Aardoom et al. (2016) found that participants who received an intervention without therapist support were significantly less satisfied $(\mathrm{M}=5.0, \mathrm{SD}=1.0$, scale $1-10)$ than participants who received an intervention with low- $(\mathrm{M}=7.1, \mathrm{SD}=1.5)$ or highintensity therapist support $(\mathrm{M}=7.4, \mathrm{SD}=1.3)$. Finally, in a post-treatment qualitative interview, participants noted that they liked the flexibility that Internet treatment offered (Sánchez-Ortiz et al., 2011) allowing, for example, access to treatment during evening and weekend hours when clinic appointments are not usually available. Hence, acceptance of Internet treatment appears satisfactory.

\section{Utility.}

It is important to distinguish between pure self-help provided, for example, in books, or via the Internet or apps, and treatment. In the former case no therapist is involved and the intent is to inform rather than to treat. The majority of the controlled studies reviewed conceptualized Internet therapy as being similar to therapist guided self-help and that 
Internet therapy should be viewed as a first-step treatment followed by specialist care if improvement is insufficient. Use of the Internet may further reduce therapist time from the already low times associated with CBTgsh, and the power of technology could be harnessed for the creation of clinical management "dashboards," allowing therapists to efficiently monitor multiple users at one time. Moreover, iCBT may be as effective as bibliotherapy and possibly guided self-help. Wilson and Zanberg (2012) point out that CBTgsh should not be relegated solely to a first step treatment, but is an effective treatment in its own right and particularly useful when highly qualified therapists are not available. Hence, iCBT may be similarly useful. The dominant model of treatment delivery in the eating disorders and other mental health fields has involved face-to-face treatment with individuals or in small units (e.g., families, groups), but this model may constrain the ability to reach large numbers of individuals in need (Kazdin \& Blase, 2011). However, the question remains: What degree of lowered effectiveness can be tolerated in shortened treatments when they are used as a firstlevel treatment? For example, in communities or situations where optimal treatment is not available, would a therapy with about half the effect of an optimal treatment be acceptable?

One aspect of utility noted in some studies was the anonymity associated with treatment via the Internet. Is it feasible and ethical to allow such anonymity? We doubt that any therapist would treat a potential patient who refuses to give a name, address, or emergency contact. As we have argued, some form of face-to-face evaluation is essential from the viewpoint of adequate care and safety. Hence, total anonymity is not possible within the bounds of medical and psychological safety.

Technology has the potential to transform some aspects of healthcare (Murdoch \& Detsky, 2013; West, 2012). Not only can technology overcome barriers to care and broaden treatment reach, but it also has the potential to maximize intervention impact by reaching patients in the settings that are most problematic for them (Chaudhry et al., 2006; Comer, 2015). Future program development should take full advantage of the capabilities of technology by using approaches such as machine learning, a type of artificial intelligence that affords computers the ability to learn without being explicitly programmed, to become acquainted with an individual's behavior patterns and subsequently deliver customized interventions during times of need (Kelly et al., 2012; Mohr, Burns, Schueller, Clarke, \& Klinkman, 2013), offering a form of personalized medicine (Ackerman, Filart, Burgess, Lee, $\&$ Poropatich, 2010). Engagement and adherence have often been an issue in technologybased CBT programs for eating disorders as well as technology-based mental health programs in general (Nitsch et al., 2016). Highly sophisticated features such as these, as well as professional quality design and enhanced user experience, will increase the likelihood that users will engage with the program. Furthermore, the majority of the Internet-based RCTs reviewed, tested programs with longer, less frequent sessions (e.g., weekly 45 minute sessions) that mimic in-person delivery, but it may be that it is most optimal for technologydelivered programs to be engaged with for shorter periods of time more frequently.

\section{Looking Ahead}

At this point there is not a strong enough evidence-base to support widespread usage of Internet treatments in the clinic. The extant studies provide a signal that effectiveness studies 
involving comparisons with known effective treatments are feasible. Hence, the studies needed now are randomized comparisons with CBTgsh or with full CBT. Given that the preferred use for Internet provided treatment is for a first step in a therapeutic sequence, such sequences should be compared with full CBT including cost-effectiveness analyses. These next steps in research will require assessments such as the EDE. It is important that online research does not use less certain assessment methods, such as solely online, selfreport evaluations, than are used in non-Internet research. Examination of the sensitivity and specificity of online questionnaire assessments of eating disorder psychopathology compared with assessments such as the EDE and Structured Clinical Interview for DSM-5 Disorders (SCID) should be prioritized. Furthermore, the programs that have been tested to date have been fairly basic in terms of form and content and have made little use of the capabilities of the Internet and technology (Loucas et al., 2014). Indeed, the majority of programs that have been tested have mimicked written self-help programs but have simply been presented online. In order to increase the potency and scalability of these interventions, they need to become more interactive and personalized in the sense that they become customized as they learn about the user. For guided interventions, the coaches' experience also needs to be optimized and made cost effective. Although much work remains to be done, the use of technology offers promise for the dissemination of CBT for eating disorders.

At this point there is no evidence-base for the use of mobile applications for the treatment of eating disorders although their use for assessment and feedback of progress to patients and therapists is clearly an advantage over the use of written self-monitoring.

\section{References}

Aardoom JJ, Dingemans AE, Spinhoven P, \& Van Furth EF (2013). Treating eating disorders over the Internet: A systematic review and future research directions. International Journal of Eating Disorders, 46, 539-552. doi:10.1002/eat.22135 [PubMed: 23674367]

Aardoom JJ, Dingemans AE, Spinhoven P, van Ginkel JR, de Rooij M, \& van Furth EF (2016). Webbased fully automated self-help with different levels of therapist support for individuals with eating disorder symptoms: A randomized controlled trial. Journal of Medical Internet Research 18:e159 doi:10.2196/jmir.5709 [PubMed: 27317358]

Aardoom JJ, Dingemans AE, \& Van Furth EF (2016). E-health interventions for eating disorders: Emerging findings, issues, and opportunities. Current Psychiatry Reports, 18, 42. doi:10.1007/ s11920-016-0673-6 [PubMed: 26946513]

Ackerman MJ, Filart R, Burgess LP, Lee I, \& Poropatich RK (2010). Developing next-generation telehealth tools and technologies: Patients, systems, and data perspectives. Telemedicine and eHealth, 16, 93-95. doi:10.1089/tmj.2009.0153 [PubMed: 20043711]

Agras WS, Schneider JA, Arnow B, Raeburn SD, \& Telch C (1989). Cognitive-behavioral and respnseprevention treatments for bulimia nervosa. Journal of Consulting and Clinical Psychology, 57, 215221. doi:10.1037/0022-006X.57.2.215 [PubMed: 2708607]

Agras WS, Telch C, Arnow B, Wilfley D, Raeburn SD, Handerson J, \& Marnell M (1994). Weight loss, cognitive-behavioral, and desipramine treatments in binge eating disorder: An additive design. Behavior Therapy, 25, 225-238. doi:10.1016/S0005-7894(05)80285-0

Agras WS, Walsh BT, Fairburn CG, Wilson GT, \& Kraemer HC (2000). A multicenter comparison of cognitive-behavioral therapy and interpersonal psychotherapy for bulimia nervosa. Archives of General Psychiatry, 57, 459-466. doi:10.1001/archpsyc.57.5.459 [PubMed: 10807486] 
Ambwani S, Cardi V, \& Treasure J (2014). Mobile self-help interventions for anorexia nervosa: Conceptual, ethical, and methodological considerations for clinicians and researchers. Professional Psychology: Research and Practice, 45, 316-323. doi:10.1037/a0036203

Anderson M (2015, 10 29). Technology device ownership: 2015. Retrieved from http:// www.pewinternet.org/2015/10/29/technology-device-ownership-2015/

Bauer S, \& Moessner M (2013). Harnessing the power of technology for the treatment and prevention of eating disorders. International Journal of Eating Disorders, 46, 508-515. doi:10.1002/eat.22109 [PubMed: 23658102]

Blom TJ, Mingione CJ, Guerdjikova AI, Keck PE, Welge JA, \& McElroy SL (2014). Placebo response in binge eating disorder: A pooled analysis of 10 clinical trials from one research group. European Eating Disorders Review, 22, 140-146. doi:10.1002/erv.2277 [PubMed: 24399652]

Bulik CM, Marcus MD, Zerwas S, Levine MD, Hofmeier S, Trace SE, ... Kordy H (2012). CBT4BN versus CBTF2F: Comparison of online versus face-to-face treatment for bulimia nervosa. Contemporary Clinical Trials, 33, 1056-1064. doi:10.1016/j.cct.2012.05.008 [PubMed: 22659072]

Carrard I, Crépin C, Rouget P, Lam T, Golay A, \& Van der Linden M (2011). Randomised controlled trial of a guided self-help treatment on the Internet for binge eating disorder. Behaviour Research and Therapy, 49, 482-491. doi:10.1016/j.brat.2011.05.004 [PubMed: 21641580]

Casper RC, Eckert ED, Halmi KA, Godlberg SC, \& Davis JM (1980). Bulimia. Its incidence and clinical importance in patients with anorexia nervosa. Archives of General Psychiatry, 37, 1030 1035. doi:10.1001/archpsyc.1980.01780220068007 [PubMed: 6932187]

Chaudhry B, Wang J, Wu S, Maglione M, Mojica W, Roth E, ... Shekelle PG (2006). Systematic review: Impact of health information technology on quality, efficiency, and costs of medical care. Annals of Internal Medicine, 144, 742-752. doi:10.7326/0003-4819-144-10-200605160-00125 [PubMed: 16702590]

Childress CA (2000). Ethical issues in providing online psychotherapeutic interventions. Journal of Medical Internet Research, 2, e5. doi:10.2196/jmir.2.1.e5 [PubMed: 11720924]

Comer JS (2015). Introduction to the special series: Applying new technologies to extend the scope and accessibility of mental health care. Cognitive and Behavioral Practice, 22, 252-257.

Debar LL, Striegel-Moore RH, Wilson GT, Perrin N, Yarborough BJ, Dickerson J, ... Kraemer HC (2011). Guided self-help treatment for recurrent binge eating: replication and extension. Psychiatric Services, 62, 367-373. doi:10.1176/ps.62.4.pss6204_0367 [PubMed: 21459987]

de Zwaan M, Herpertz S, Zipfel S, Tuschen-Caffier B, Friederich H, Schmidt F, ... Hilbert A (2012). INTERBED: Internet-based guided self-help for overweight and obese patients with full or subsyndromal binge eating disorders. A multicenter randomized controlled trial. Trials, 13, 220. doi:10.1186/1745-6215-13-220 [PubMed: 23171536]

Dölemeyer R, Tietjen A, Kersting A, \& Wagner B (2013). Internet-based interventions for eating disorders in adults: A systematic review. BMC Psychiatry, 13, 207. doi: 10.1186/1471-244X-13-207 [PubMed: 23919625]

Eisenberg D, Nicklett EJ, Roeder K, \& Kirz NE (2011). Eating disorder symptoms among college students: Prevalence, persistence, correlates, and treatment-seeking. Journal of American College Health, 59, 700-707. doi:10.1080/07448481.2010.546461 [PubMed: 21950250]

Fairburn CG (1981). A cognitive-behavioural approach in the management of bulimia. Psychological Medicine, 11, 707-711. doi:10.1017/S0033291700041209 [PubMed: 6948316]

Fairburn CG, Cooper Z, \& Palmer RL (2009). Transdiagnostic cognitive-behavioral therapy for patients with eating disorders: A two-site trial with 60-week follow-up. American Journal of Psychiatry, 166, 311-319. doi:10.1176/appi.ajp.2008.08040608 [PubMed: 19074978]

Fairburn CG (2008). Cognitive behavior therapy and eating disorders. Guilford Press: New York.

Fairburn CG, Jones R, Peveler RC, Carr SJ, Solomon RA, O'Conner ME, ... Hope RA (1991). Three psychological treatments for bulimia nervosa. Archives of General Psychiatry, 48, 463-469. doi: 10.1001/archpsyc.1991.01810290075014 [PubMed: 2021299]

Fairburn CG, Jones R, Peveler RC, Hope RA, \& O’Connor M (1993a). Longer-term effects of interpersonal psychotherapy, behavior therapy, and cognitive-behavior therapy. Archives of General Psychiatry, 50, 419-428. doi:10.1001/archpsyc.1993.01820180009001 [PubMed: 8498876] 
Fairburn CG, Bailey-Straebler S Basden S, Doll HA, Jones R, Murphy R, ... Cooper Z (2015). A transdiagnostic comparison of enhanced cognitive bheavioral therapy (CBT-E) and interpersonal psychotherapy in the treatment of eating disorders. Behaviour Research and Therapy, 70, 64-71. doi:10.1016/j.brat.2015.04.010 [PubMed: 26000757]

Fairburn CG, Kirk J, O’Connor M, \& Cooper PJ (1986). A comparison of two psychological treatments for bulimia nervosa. Behaviour Research and Therapy, 24, 629-643. doi: 10.1016/0005-7967(86)90058-6 [PubMed: 3800834]

Fairburn CG, \& Rothwell ER (2015). Apps and eating disorders: A systematic clinical appraisal. International Journal of Eating Disorders, 48, 1038-1046. doi:10.1002/eat.22398 [PubMed: 25728705]

Fairburn CG, Welch SL, \& Hay P (1993b). The classification of recurrent overeating: The binge eating disorder proposal. International Journal of Eating Disorders, 13, 155-159. doi: 10.1002/1098-108X(199303)13:2<155::AID-EAT2260130203>3.0.CO;2-T [PubMed: 8477284]

Fairburn CG \& Wilson GT (2013). The dissemination and implementation of psychological treatments: Problems and solutions. International Journal of Eating Disorders, 46, 516-521. doi: 10.1002/eat.22110 [PubMed: 23658103]

Garner DM, Rockert W, Davis R, Garner MV, Olmsted MP, \& Eagle M (1993). Comparison of cognitive-behavioral therapy and supportive-expressive therapy for bulimia nervosa. American Journal of Psychiatry, 150, 37-46. doi:10.1176/ajp.150.1.37 [PubMed: 8417578]

Guiora AZ (1967). Dysorexia: A psychopathological study of anorexia nervosa and bulimia. American Journal of Psychiatry, 124, 391-393. doi:10.1176/ajp.124.3.391 [PubMed: 5232225]

Halmi KA, Falk JR \& Schwartz E (1981). Binge eating and vomiting: A survey of a college population. Psychological Medicine, 11, 697-706. doi:10.1017/S0033291700041192 [PubMed: 6948315]

Hart LM, Granillo MT, Jorm AF, \& Paxton SJ (2011). Unmet need for treatment in the eating disorders: A systematic review of eating disorder specific treatment seeking among community cases. Clinical Psychology Review, 31, 727-735. doi:10.1016/j.cpr.2011.03.004 [PubMed: 21501580]

Hay P, Chinn D, Forbes D, Madden S, Newton R, Sugenor L, ... Ward W (2014). Royal Australian and New Zealand College of Psychiatrists clinical practice guidelines for the treatment of eating disorders. Australian and New Zealand Journal of Psychiatry, 48, 977-1008. doi: 10.1177/0004867414555814 [PubMed: 25351912]

Heron KE, \& Smyth JM (2010). Ecological momentary interventions: Incorporating mobile technology into psychosocial and health behaviour treatments. British Journal of Health Psychology, 15, 1-39. doi:10.1348/135910709X466063 [PubMed: 19646331]

Hsin H, Torous J, \& Roberts L (2016). An adjuvant role for mobile health in psychiatry. JAMA Psychiatry, 73, 103-104. doi:10.1001/jamapsychiatry.2015.2839 [PubMed: 26747695]

Insel TR (2009). Translating scientific opportunity into public health impact. Archives of General Psychiatry, 66, 128-133. doi:10.1001/archgenpsychiatry.2008.540 [PubMed: 19188534]

Internet users (per 100 people). (n.d.). Retrieved from http://data.worldbank.org/indicator/ IT.NET.USER.P2

Jacobi C, Völker U, Trockel MT, \& Taylor CB (2012). Effects of an Internet-based intervention for subthreshold eating disorders: A randomized controlled trial. Behaviour Research and Therapy, 50, 93-99. doi:10.1016/j.brat.2011.09.013 [PubMed: 22137366]

Jones M, Luce KH, Osborne MI, Taylor K, Cunning D, Doyle AC, Taylor CB (2008). Randomized, controlled trial of an Internet-facilitated intervention for reducing binge eating and overweight in adolescents. Pediatrics, 121, 453-462. doi:10.1542/peds.2007-1173 [PubMed: 18310192]

Juarascio AS, Manasse SM, Goldstein SP, Forman EM, \& Butryn ML (2014). Review of smartphone applications for the treatment of eating disorders. European Eating Disorders Review, 23, 1-11. doi:10.1002/erv.2327 [PubMed: 25303148]

Kaplan RM, \& Stone AA (2013). Bringing the laboratory and clinic to the community: Mobile technologies for health promotion and disease prevention. Annual Review of Psychology, 64, 471498. doi:10.1146/annurev-psych-113011-143736 
Kazdin AE, \& Blase SL (2011). Rebooting psychotherapy research and practice to reduce the burden of mental illness. Perspectives on Psychological Science, 6, 21-37. doi: 10.1177/1745691610393527 [PubMed: 26162113]

Kelly J, Gooding P, Pratt D, Ainsworth J, Welford M, \& Tarrier N (2012). Intelligent real-time therapy: Harnessing the power of machine learning to optimise the delivery of momentary cognitivebehavioural interventions. Journal of Mental Health, 21, 404-414. doi: 10.3109/09638237.2011.638001 [PubMed: 22251028]

Kraemer HC, Wilson GT, Fairburn CG, \& Agras WS (2002). Mediators and moderators of treatment effects in randomized clinical trials. Archives of General Psychiatry, 59, 877-883. doi:10.1001/ archpsyc.59.10.877 [PubMed: 12365874]

Kurzweil R (2010, 12 28). Technology 25 years hence. The New York Times. Retrieved from http:// www.nytimes.com/roomfordebate/2010/12/27/why-do-we-need-to-predict-the-future/ technology-25-years-hence

Lal S, \& Adair CE (2014). E-mental health: A rapid review of the literature. Psychiatric Services, 65, 24-32. doi:10.1176/appi.ps.201300009 [PubMed: 24081188]

Leitenberg H, Rosen JC, Gross J, Nudelman S, \& Vara LS (1988). Exposure plus response-prevention in treatment of bulimia nervosa. Journal of Consulting and Clinical Psychology, 56, 535-541. doi: 10.1037/0022-006X.56.4.535 [PubMed: 3198810]

Ljotsson B, Lundin C, Mitsell K, Carlbring P, Ramklint M, \& Ghaderi A (2007). Remote treatment of bulimia nervosa and binge eating disorder: A randomized trial of Internet-assisted cognitive behavioural therapy. Behaviour Research and Therapy, 45, 649-661. doi:10.1016/j.brat.2006.010 [PubMed: 16899213]

Loucas CE, Fairburn CG, Whittington C, Pennant ME, Stockton S, \& Kendall T (2014). E-therapy in the treatment and prevention of eating disorders: A systematic review and meta-analysis. Behaviour Research and Therapy, 63, 122-131. doi:10.1016/j.brat.2014.09.011 [PubMed: 25461787]

Marcus MD, Wing RR, \& Fairburn CG (1995). Cognitive-behavioral treatment of binge eating vs. behavioral weight control on the treatment of binge eating disorder. Annals of Behavioral Medicine, 17, S90.

McCann UD \& Agras WS (1990). Successful treatment of nonpurging bulimia nervosa with desipramine: A double-blind placebo-controlled study. American Journal of Psychiatry, 147, 1509-1513. doi:10.1176/ajp.147.11.1509 [PubMed: 2221164]

Mitchell JE, Agras WS, Crow S, Halmi KA, Fairburn CG, Bryson S, \& Kraemer HC (2011). Stepped care and cognitive-behavioural therapy for bulimia nervosa: Randomised trial. British Journal of Psychiatry, 198, 391-397. doi:10.1192/bjp.bp.110.082172 [PubMed: 21415046]

Mohr DC, Burns MN, Schueller SM, Clarke G, \& Klinkman M (2013). Behavioral intervention technologies: Evidence review and recommendations for future research in mental health. General Hospital Psychiatry, 35, 332-338. doi:10.1016/j.genhosppsych.2013.03.008 [PubMed: 23664503]

Mohr DC, Schueller SM, Riley WT, Brown CH, Cuijpers P, Duan N, ... Cheung K (2015). Trials of intervention principles: Evaluation methods for evolving behavioral intervention technologies. Journal of Medical Internet Research, 17, e166. doi:10.2196/jmir.4391 [PubMed: 26155878]

Murdoch TB, \& Detsky AS (2013). The inevitable application of big data to health care. JAMA, 309, 1351-1352. doi:10.1001/jama.2013.393 [PubMed: 23549579]

Nitsch M, Dimopoulos CN, Flaschberger E, Saffran K, Kruger JF, Garlock L, ... Jones M (2016). A guided online and mobile self-help program for individuals with eating disorders: An iterative engagement and usability study. Journal of Medical Internet Research, 18, e7. doi:10.2196/jmir. 4972 [PubMed: 26753539]

O’Toole J (2014, 2 28). Mobile apps overtake PC Internet usage in U.S. CNN Money. Retrieved from http://money.cnn.com/2014/02/28/technology/mobile/mobile-apps-internet/

Perez S (2015, 6 22). Consumers spend 85\% of time on smartphones in apps, but only 5 apps see heavy use. TechCrunch. Retrieved from http://techcrunch.com/2015/06/22/consumers-spend-85of-time-on-smartphones-in-apps-but-only-5-apps-see-heavy-use/ 
Robinson P, \& Serfaty M (2008). Getting better byte by byte: A pilot randomised controlled trial of email therapy for bulimia nervosa and binge eating disorder. European Eating Disorders Review, 16, 84-93. doi:10.1002/erv.818 [PubMed: 17879223]

Russell GFM (1979). Bulimia nervosa: An ominous variant of anorexia nervosa. Psychological Medicine, 9, 429-448. doi:10.1017/S0033291700031974 [PubMed: 482466]

Ruwaard J, Lange A, Broeksteeg J, Renteria-Agirre A, Schrieken B, Dolan CV, \& Emmelkamp P (2013). Online cognitive-behavioural treatment of bulimic symptoms: A randomized controlled trial. Clinical Psychology and Psychotherapy, 20, 308-318. doi:10.1002/cpp.1767 [PubMed: 22298417]

Saekow J, Jones M, Gibbs E, Jacobi C, Fitzsimmons-Craft EE, Wilfley D, \& Taylor CB (2015). StudentBodies-eating disorders: A randomized controlled trial of a coached online intervention for subclinical eating disorders. Internet Interventions, 2, 419-428. doi:10.1016/j.invent.2015.10.004

Sánchez-Ortiz VC, Munro C, Stahl D, House J, Startup H, Treasure J, ... Schmidt U (2011). A randomized controlled trial of internet-based cognitive-behavioural therapy for bulimia nervosa or related disorders in a student population. Psychological Medicine, 41, 407-417. doi:10.1017/ S0033291710000711 [PubMed: 20406523]

Schlegel S, Bürger C, Schmidt L, Herbst N, \& Voderholzer U (2015). The potential of technologybased psychological interventions for anorexia and bulimia nervosa: A systematic review and recommendations for future research. Journal of Medical Internet Research, 17, e85. doi:10.2196/ jmir.3554 [PubMed: 25840591]

Schmidt U, Andiappan M, Grover M, Robinson S, Perkins S, Dugmore O, ... Williams C (2008). Randomised controlled trial of CD-ROM-based cognitive-behavioural self-care for bulimia nervosa. The British Journal of Psychiatry, 193, 493-500. doi:10.1192/bjp.bp.107.046607 [PubMed: 19043154]

Schmidt U, \& Wykes T (2012). E-mental health - a land of unlimited possibilities. Journal of Mental Health, 21, 327-331. doi:10.3109/09638237.2012.705930 [PubMed: 22823092]

Shapiro JR, Reba-Harrelson L, Dymek-Valentine M, Woolson SL, Hamer RM, \& Bulik CM (2007). Feasibility and acceptability of CD-ROM-based cognitive-behavioural treatment for binge-eating disorder. European Eating Disorders Review, 15, 175-184. doi:10.1002/erv.787 [PubMed: 17676687]

Shingleton RM, Richards LK, \& Thompson-Brenner H (2013). Using technology within the treatment of eating disorders: A clinical practice review. Psychotherapy, 50, 576-582. doi:10.1037/a0031815 [PubMed: 23527906]

Simon GE, Revicki D, \& VonKorff M (1993). Telephone assessment of depression severity. Journal of Psychiatric Research, 27, 247-251. doi:10.1016/0022-3956(93)90035-Z [PubMed: 8295157]

Spitzer RL (1991). Non-purging bulimia nervosa and binge eating disorder. American Journal of Psychiatry, 148, 1097-1098. doi:10.1176/ajp.148.8.1097-a [PubMed: 1853974]

Spitzer RL, Stunkard AJ, Yanovski JA, Marcus MD, Wadden T, Wing RR, ... Hasin D (1993). Binge eating disorder should be included in DSM-IV: A reply to Fairburn et al.'s proposal. International Journal of Eating Disorders, 13, 161-169. doi:10.1002/1098-108X(199303)13:2<161::AIDEAT2260130204>3.0.CO;2-R [PubMed: 8477285]

Steinhausen HC \& Weber S (2009). The outcome of bulimia nervosa: Findings from one- quarter century of research. American Journal of Psychiatry, 166, 1331-1341. doi:10.1176/appi.ajp. 2009.09040582 [PubMed: 19884225]

Telch C, Agras WS, Rossiter EM, Wilfley D, \& Kenardy J (1990). Group cognitive-behavioral treatment for the nonpurging bulimic. Journal of Consulting and Clinical Psychology, 58, 629635. doi:10.1037/0022-006X.58.5.629 [PubMed: 2254511]

ter Huurne ED, de Haan HA, Postel MG, van der Palen J, VanDerNagel JE, \& DeJong CA (2015). Web-based cognitive behavioral therapy for female patients with eating disorders: Randomized controlled trial. Journal of Medical Internet Research, 17, e152. doi:10.2196/jmir.3946 [PubMed: 26088580]

Thompson-Brenner H, Shingleton RM, Thompson DR, Richards LK, Pratt EM, \& Barlow DH (2016). Focused vs. broad enhanced cognitive-behavioral therapy for bulimina nervosa with comorbid 
borderline personality: A randomized controlled trial. International Journal of Eating Disorders, 49, 36-49. doi:10.1002/eat.22468 [PubMed: 26649812]

Wagner B, Nagl M, Dölemeyer R, Klinitzke G, Steinig J, Hilbert A, \& Kersting A (2016). Randomized controlled trial of an Internet-based cognitive-behavioral treatment program for binge-eating disorder. Behavior Therapy, 47, 500-514. doi:10.1016/j.beth.2016.01.006 [PubMed: 27423166]

Wagner G, Penelo E, Wanner C, Gwinner P, Trofaier M, Imgart H, ... Karwautz AFK (2013). Internetdelivered cognitive-behavioural therapy v. conventional guided self-help for bulimia nervosa: Long-term evaluation of a randomised controlled trial. The British Journal of Psychiatry, 202, 135-141. doi:10.1192/bjp.bp.111.098582 [PubMed: 23222037]

West D (2012). How mobile devices are transforming healthcare. Issues in Technology Innovation, 18, $1-14$.

Wilfley DE, Agras WS, \& Taylor CB (2013). Reducing the burden of eating disorders: A model for population-based prevention and treatment for university and college campuses. International Journal of Eating Disorders, 46, 529-532. doi:10.1002/eat.22117 [PubMed: 23658106]

Wilfley DE, Agras WS, Telch CF, Rossiter EM, Schneider JA, Cole AB, ... Raeburn SD (1993). Group cognitive-behavioral therap and group interpersonal psychotherapy for the non-purging bulimic: A controlled comparison. Journal of Consulting and Clinical Psychology, 61, 296-305. doi: 10.1037/0022-006X.61.2.296 [PubMed: 8473584]

Wilfley DE, Welch RR, Stein RI, Spurrell EB, Cohen LR, Saelens BE, ... Matt GE (2002). A randomized comparison of group cognitive-behavioral therapy and group interpersonal psychotherapy for the treatment of overweight individuals with binge-eating disorder. Archives of General Psychiatry, 59, 713-721. doi: 10.1001/archpsyc.59.8.713 [PubMed: 12150647]

Wilson GT, Fairburn CG, Agras WS, \& Walsh BT (2002). Cognitive behavior therapy for bulimia nervosa: Time course and mechanisms of change. Journal of Consulting and Clinical Psychology, 70, 267-274. doi:10.1037/0022-006X.70.2.267 [PubMed: 11952185] 
Table 1

Overview of randomized controlled trials that have utilized technology for CBT delivery with individuals with clinical eating disorders

\begin{tabular}{|c|c|c|c|c|c|}
\hline Study & Study Population & $\begin{array}{l}\text { Intervention/ } \\
\text { Level of Support } \\
\text { Provided }\end{array}$ & $\begin{array}{l}\text { Control Condition/ } \\
\text { Comparison Intervention(s) }\end{array}$ & $\begin{array}{l}\text { Intervention Duration/ } \\
\text { Post-Assessment and } \\
\text { Main Results }\end{array}$ & $\begin{array}{l}\text { Follow-Up and } \\
\text { Main Results }\end{array}$ \\
\hline \multicolumn{6}{|c|}{ CD-ROM } \\
\hline $\begin{array}{l}\text { Schmidt et } \\
\text { al., } 2008\end{array}$ & $\begin{array}{l}97 \text { adults with } \mathrm{BN} \text { or } \\
\text { EDNOS }(97 \% \text { female; } \\
M \text { age }=27.1, S D= \\
7.6)\end{array}$ & $\begin{array}{l}\text { "Overcoming } \\
\text { Bulimia" CD- } \\
\text { ROM CBT } \\
\text { Support: Not } \\
\text { guided }\end{array}$ & Waitlist & $\begin{array}{l}3 \text { months } \\
\text { Significant group } \times \text { time } \\
\text { interaction for binge } \\
\text { eating and vomiting } \\
\text { favoring CD-ROM CBT } \\
\text { but post hoc group } \\
\text { comparisons not } \\
\text { significant }\end{array}$ & $\begin{array}{l}4 \text { months } \\
\text { Significant group } \\
\times \text { time interaction } \\
\text { for binge eating } \\
\text { and vomiting } \\
\text { favoring waitlist } \\
\text { but post hoc group } \\
\text { comparisons not } \\
\text { significant }\end{array}$ \\
\hline $\begin{array}{l}\text { Shapiro et } \\
\text { al., } 2007\end{array}$ & $\begin{array}{l}66 \text { overweight adults } \\
\text { with full or } \\
\text { subthreshold BED } \\
(92 \% \text { female; } M \text { age = } \\
39.6, S D=11.7)\end{array}$ & $\begin{array}{l}\text { CD-ROM CBT } \\
\text { Support: Not } \\
\text { guided but had } \\
\text { one telephone } \\
\text { contact per week } \\
\text { with research } \\
\text { assistant to } \\
\text { address technical } \\
\text { difficulties }\end{array}$ & $\begin{array}{l}\text { In-person group CBT } \\
\text { Waitlist }\end{array}$ & $\begin{array}{l}10 \text { weeks } \\
\text { No differences between } \\
\text { groups on most outcome } \\
\text { measures; no differences } \\
\text { in abstinence from binge } \\
\text { eating (13.3\% in CD- } \\
\text { ROM CBT vs. } 7.7 \% \text { in } \\
\text { group CBT vs. } 0 \% \text { in } \\
\text { waitlist) }\end{array}$ & $\begin{array}{l}8 \text { weeks } \\
\text { Significantly } \\
\text { greater decline in } \\
\text { binge days in CD- } \\
\text { ROM CBT and } \\
\text { group CBT } \\
\text { relative to waitlist }\end{array}$ \\
\hline \multicolumn{6}{|c|}{ E-mail } \\
\hline $\begin{array}{l}\text { Ljotsson } \\
\text { et al., } \\
2007\end{array}$ & $\begin{array}{l}73 \text { adults with full or } \\
\text { subthreshold BN or } \\
\text { BED }(94 \% \text { female; } \\
\text { Internet-assisted self- } \\
\text { help: } M \text { age }=35.5, S D \\
=11.4 \text {; WL: } M \text { age }= \\
33.7, S D=9.3)\end{array}$ & $\begin{array}{l}\text { Internet-assisted } \\
\text { self-help } \\
\text { Support: once- to } \\
\text { twice-weekly } \\
\text { email contact } \\
\text { with a } \\
\text { psychology } \\
\text { graduate student } \\
\text { for support and } \\
\text { feedback and } \\
\text { access to an } \\
\text { online discussion } \\
\text { group }\end{array}$ & Waitlist & $\begin{array}{l}12 \text { weeks } \\
\text { Greater reductions in } \\
\text { binge eating and most } \\
\text { EDE-Q and EDI-2 } \\
\text { subscales in Internet- } \\
\text { assisted self-help vs. } \\
\text { waitlist; } 37 \% \text { in Internet- } \\
\text { assisted self-help were } \\
\text { abstinent from binge } \\
\text { eating and purging vs. } \\
15 \% \text { in waitlist }\end{array}$ & $\begin{array}{l}6 \text { months } \\
\text { Results were } \\
\text { maintained at } \\
\text { follow-up }\end{array}$ \\
\hline $\begin{array}{l}\text { Robinson } \\
\text { \& Serfaty, } \\
2008\end{array}$ & $\begin{array}{l}97 \text { adults with BN, } \\
\text { BED, or EDNOS ( } \% \\
\text { female not provided; } \\
\text { email-based CBT: } M \\
\text { age }=24.5, S D \text { not } \\
\text { provided) }\end{array}$ & $\begin{array}{l}\text { Email-based } \\
\text { CBT } \\
\text { Support: Twice- } \\
\text { weekly email } \\
\text { contact with } \\
\text { therapist }\end{array}$ & $\begin{array}{l}\text { Self-directed writing } \\
\text { Waitlist }\end{array}$ & $\begin{array}{l}3 \text { months } \\
\text { Significantly fewer } \\
\text { email-based CBT and } \\
\text { self-directed writing } \\
\text { participants fulfilled } \\
\text { criteria for an eating } \\
\text { disorder compared to } \\
\text { waitlist }\end{array}$ & $\mathrm{n} / \mathrm{a}$ \\
\hline \multicolumn{6}{|c|}{ Internet } \\
\hline $\begin{array}{l}\text { Sánchez- } \\
\text { Ortiz et } \\
\text { al., } 2011\end{array}$ & $\begin{array}{l}76 \text { college students } \\
\text { with BN or EDNOS } \\
(99 \% \text { female; } M \text { age }= \\
23.9, S D=5.9)\end{array}$ & $\begin{array}{l}\text { "Overcoming } \\
\text { Bulimia" iCBT } \\
\text { Support: email } \\
\text { support from } \\
\text { therapist every 1- } \\
2 \text { weeks and } \\
\text { responding as } \\
\text { questions arose }\end{array}$ & Waitlist & $\begin{array}{l}3 \text { months } \\
\text { iCBT superior to waitlist } \\
\text { on EDE Global and } \\
\text { binge eating }\end{array}$ & $\begin{array}{l}3 \text { months } \\
\text { Gains were } \\
\text { maintained or } \\
\text { continued to } \\
\text { improve during } \\
\text { follow-up; } 39 \% \text { in } \\
\text { iCBT were } \\
\text { abstinent from } \\
\text { binge eating and } \\
\text { purging vs. } 21 \% \text { in } \\
\text { waitlist; } 52 \% \text { in } \\
\text { iCBT did not meet } \\
\text { criteria for an } \\
\text { eating disorder vs. } \\
29 \% \text { in waitlist }\end{array}$ \\
\hline
\end{tabular}




\begin{tabular}{|c|c|c|c|}
\hline Study & Study Population & $\begin{array}{l}\text { Intervention/ } \\
\text { Level of Support } \\
\text { Provided }\end{array}$ & $\begin{array}{l}\text { Control Condition/ } \\
\text { Comparison Intervention(s) }\end{array}$ \\
\hline $\begin{array}{l}\text { Ruwaard } \\
\text { et al., } \\
2013\end{array}$ & $\begin{array}{l}105 \text { adults with } \\
\text { moderate to severe } \\
\text { bulimic symptoms } \\
\text { ( } 99 \% \text { female; } M \text { age = } \\
31, S D \text { not provided) }\end{array}$ & $\begin{array}{l}\text { iCBT } \\
\text { Support: } 25 \\
\text { scheduled online } \\
\text { therapist } \\
\text { feedback } \\
\text { moments ( } 13 \mathrm{hrs})\end{array}$ & $\begin{array}{l}\text { Bibliotherapy: hard copy of } \\
\text { self-help book with no } \\
\text { therapist support } \\
\text { Waitlist }\end{array}$ \\
\hline
\end{tabular}

\section{Intervention Duration/ Follow-Up and Post-Assessment and Main Results \\ Main Results}

\section{0 weeks}

iCBT superior to

bibliotherapy and

waitlist on binge/purge

frequency and EDE-Q

Global; iCBT more

likely to be abstinent

from purging (39\% in

iCBT vs. $8 \%$ in

bibliotherapy and

waitlist); no differences

in abstinence from binge

eating

\begin{tabular}{ll}
\hline Wagner et & 155 adult females with \\
al., 2013 & BN or EDNOS (iCBT: \\
& $M$ age $=24.2, S D=$ \\
& 4.5 ; guided \\
& bibliotherapy: $M$ age $=$ \\
& $25.0, S D=3.8)$
\end{tabular}

iCBT

Support: Weekly copy of self-help book with

4-7 months

weekly email support from

therapist

No difference between

treatments in binge

eating, vomiting, and

fasting; no differences in

rates of abstinence or

remission (47\% in iCBT

vs. $49 \%$ in guided

bibliotherapy)

\begin{tabular}{lll}
\hline Carrard et & 74 adult females with & iCBT \\
al., 2011 & full or subthreshold & Support: Weekly \\
& BED $(M$ age $=36.0$, & email support \\
& $S D=11.4)$ & from therapist \\
& & during \\
& & intervention and \\
& monthly email \\
& & contact during \\
& & follow-up period
\end{tabular}

6 months

Significant

improvements on EDI-2

Bulimia, frequency of

objective binge eating

episodes, self-esteem,

and quality of life in

iCBT compared to

waitlist; significant

difference in abstinence

rate $35 \%$ in $\mathrm{iCBT}$ vs.

$8 \%$ in waitlist)

\begin{tabular}{ll}
\hline Wagner et & 139 adults with BED \\
al., 2016 & $(96 \%$ female; $M$ age $=$ \\
& $35.1, S D=9.9)$
\end{tabular}

iCBT

16 weeks

iCBT superior to waitlist

on frequency of

objective binge eating

episodes, EDE-Q Global

and all subscales,

depression, and weight

loss but no difference on

anxiety

\begin{tabular}{llll}
\hline ter Huurne & 214 adult females with & iCBT & Waitlist \\
et al., & BN, BED, or EDNOS & Support: Contact & \\
2015 & $(M$ age $=39.4, S D=$ & with therapists & \\
& $11.6)$ & 2×/week via & \\
& & Internet &
\end{tabular}

1 year

Differences

between $\mathrm{iCBT}$ and

bibliotherapy no

longer significant

due to

improvements in

bibliotherapy; no

differences in

abstinence from

purging

\section{1-14 months}

No difference

between

treatments in binge eating, vomiting, and fasting

6 months

All gains were

sustained or

continued to

improve in iCBT binge eating or
15-18 weeks

iCBT superior to waitlist

on improvements in

EDE-Q Global, body

dissatisfaction, physical

health, mental health,

self-esteem, and social

functioning; between-

only for participants

with BED (not BN or

EDNOS) group effect significant

\begin{tabular}{|c|c|c|c|c|c|}
\hline $\begin{array}{l}\text { Aardoom } \\
\text { et al., } \\
2016\end{array}$ & $\begin{array}{l}354 \text { participants with } \\
\text { AN, BN, or BED }(99 \% \\
\text { female; } M \text { age }=24.2, \\
S D=7.7)\end{array}$ & $\begin{array}{l}\text { Featback } \\
\text { Support: Fully } \\
\text { automated } \\
\text { feedback system } \\
\text { vs. automated } \\
\text { feedback + low- } \\
\text { intensity } \\
\text { (weekly) digital } \\
\text { therapist support } \\
\text { vs. automated } \\
\text { feedback + high- } \\
\text { intensity (3 times }\end{array}$ & Waitlist & $\begin{array}{l}8 \text { weeks } \\
\text { The } 3 \text { Featback } \\
\text { conditions superior to } \\
\text { waitlist on bulimic } \\
\text { psychopathology, } \\
\text { symptoms of depression } \\
\text { and anxiety, and } \\
\text { perseverative thinking }\end{array}$ & $\begin{array}{l}3 \text { months and } 6 \\
\text { months } \\
\text { The } 3 \text { Featback } \\
\text { conditions superior } \\
\text { to waitlist in } \\
\text { improvements on } \\
\text { eating disorder- } \\
\text { related quality of } \\
\text { life and symptoms } \\
\text { of depression } \\
\text { anxiety from post- } \\
\text { treatment to 3- }\end{array}$ \\
\hline
\end{tabular}

Behav Res Ther: Author manuscript; available in PMC 2018 September 13. 


\begin{tabular}{|c|c|c|c|c|c|}
\hline Study & Study Population & $\begin{array}{l}\text { Intervention/ } \\
\text { Level of Support } \\
\text { Provided }\end{array}$ & $\begin{array}{l}\text { Control Condition/ } \\
\text { Comparison Intervention(s) }\end{array}$ & $\begin{array}{l}\text { Intervention Duration/ } \\
\text { Post-Assessment and } \\
\text { Main Results }\end{array}$ & $\begin{array}{l}\text { Follow-Up and } \\
\text { Main Results }\end{array}$ \\
\hline & & $\begin{array}{l}\text { a week) digital } \\
\text { therapist support }\end{array}$ & & & $\begin{array}{l}\text { month follow-up; } \\
\text { no added value of } \\
\text { therapist support } \\
\text { found in terms of } \\
\text { symptom } \\
\text { reduction over } \\
\text { time, but those } \\
\text { who received } \\
\text { support were more } \\
\text { satisfied }\end{array}$ \\
\hline
\end{tabular}

Note. $\mathrm{BN}=$ bulimia nervosa. $\mathrm{BED}=$ binge eating disorder. $\mathrm{EDNOS}=$ eating disorder not otherwise specified. $\mathrm{EDE}=$ Eating Disorder Examination. EDE-Q = Eating Disorder Examination-Questionnaire. EDI-2 = Eating Disorder Inventory-2. iCBT = Internet-based CBT. 


\section{Table 2}

Resources for ethical guidance in the use of technology in mental health intervention delivery

\begin{tabular}{lll}
\hline Resource & Link & https://www.counseling.org/resources/aca-code-of-ethics.pdf \\
\hline $\begin{array}{l}\text { American Counseling Association: Code of ethics - distance } \\
\text { counseling, technology, and social media }\end{array}$ & http://www.apa.org/practice/guidelines/telepsychology.aspx \\
\hline $\begin{array}{l}\text { American Psychological Association: Guidelines for the practice } \\
\text { of telepsychology }\end{array}$ & http://www.cpa.ca/aboutcpa/committees/ethics/psychserviceselectronically/ \\
\hline $\begin{array}{l}\text { Canadian Psychological Association: Ethical guidelines for } \\
\text { psychologists providing services via electronic media }\end{array}$ & http://www.ncbi.nlm.nih.gov/pmc/articles/PMC1761841/ \\
\hline $\begin{array}{l}\text { Childress (2000) in Journal of Medical Internet Research: Ethical } \\
\text { issues in providing online psychotherapeutic interventions }\end{array}$ & http://psychologistsboard.org.nz/cms_show_download.php?id=141 \\
\hline $\begin{array}{l}\text { New Zealand Psychological Association: Psychology services } \\
\text { delivered via the Internet and other electronic media }\end{array}$ & \\
\hline
\end{tabular}

Behav Res Ther: Author manuscript; available in PMC 2018 September 13. 